\title{
Pacific Canada's Rockfish Conservation Areas: using Ostrom's design principles to assess management effectiveness
}

\author{
Darienne Lancaster $^{1}$, Dana R. Haggarty ${ }^{2}$ and Natalie C. Ban ${ }^{1}$
}

\begin{abstract}
International declines in marine biodiversity have lead to the creation of marine protected areas and fishery reserve systems. In Canada, 164 Rockfish Conservation Areas (RCAs) were implemented between 2003 and 2007 and now cover 4847.2 km² of ocean. These reserves were created in response to widespread concern from fishers and nongovernmental organizations about inshore rockfish (genus Sebastes) population declines. We used the design principles for effective common-pool resource management systems, originally developed by Elinor Ostrom, to assess the social and ecological effectiveness of these conservation areas more than 10 years after their initial implementation. We assessed the relative presence or absence of each design principle within current RCA management. We found that 2 of the 11 design principles were moderately present in the recreational fishery. All other design principles were lacking for the recreational sector. We found that 2 design principles were fully present and 5 were moderately present in the commercial sector. Four design principles were lacking in the commercial sector. Based on this analysis, we highlight 4 main areas for management improvement: (1) create an education and outreach campaign to explain RCA rules, regulations, boundaries, and the need for marine conservation; (2) increase monitoring of users and resources to discourage noncompliance and gather the necessary data to create social buy-in for marine conservation; (3) encourage informal nested governance through stakeholder organizations for education and self-regulation (e.g. fisher to fisher); and (4) most importantly, create a formal, decadal RCA review process to gather stakeholder input and make amendments to regulations and RCA boundaries. This information can be used to inform spatial management systems both in Canada and internationally. This analysis also contributes to a growing literature on effectively scaling up small-scale management techniques for large-scale, often federally run, common-pool resource systems.
\end{abstract}

Key Words: design principles; management effectiveness; marine protected areas (MPAs); Rockfish Conservation Areas (RCAs)

\section{INTRODUCTION}

Declines in marine biodiversity and biomass are a concern for fisheries and conservation, with spatial management, including marine protected areas (MPAs) and fisheries closures, recommended as key tools to recover depleted populations (Pauly et al. 2002, Worm et al. 2009). Fishing is one of the primary human causes of marine degradation (Norse 1993, Pauly et al. 1998, Jackson 2001, Lotze et al. 2006). Despite the high fecundity of many marine fishes, overfishing of target species can reduce populations and induce trophic cascades throughout marine ecosystems (Hutchings 2001, Pauly et al. 2002, Hutchings and Reynolds 2004, Essington et al. 2006, Branch et al. 2010). In recent decades, marine conservation areas and other spatial management tools have become popular for conserving threatened marine populations (Kritzer 2004). When implemented in tandem with catch limitations and fishing fleet reductions, spatial management has been shown to effectively protect marine species and recover depleted populations (Allison et al. 1998, Pauly et al. 1998, Mosquera et al. 2000, Halpern 2003, Babcock et al. 2010).

Assessments of the effectiveness of spatial closures are important to ensure that management measures are meeting their goals. Biological effectiveness is commonly assessed (e.g., biomass, abundance, density), although there is a growing recognition that social factors such as compliance, monitoring, and enforcement are crucially important in determining biological effectiveness (Pollnac et al. 2010). One framework relevant for examining ecological and social effectiveness in common-pool resource systems, including fisheries, is the design principles developed by Ostrom (1990). This framework was re-examined and expanded from 8 to 11 principles by Cox et al. (2010) to address more of the complexity of managing these systems. They include principles such as clearly defined boundaries and monitoring of the common-pool resource. Based on a review of 91 studies conducted by Cox et al. (2010), the presence of these design principles appears to promote long-lasting, socially and ecologically effective common-pool resource management systems (Ostrom 2009). The design principles originally emerged from studies examining community-based systems (i.e., where communities organize themselves to manage their resources), but their relevance to larger systems is an area of active study. For example, the design principles have been scaled up for large systems like the Great Barrier Reef Marine Park, the International Convention for the Conservation of Atlantic Tuna, and the BC Carbon Tax (Epstein et al. 2014, Lacroix and Richards 2015).

\section{ROCKFISH BIOLOGY}

Rockfish (genus Sebastes) on the west coast of North America are particularly vulnerable to fishing pressure, with large declines having been observed and closures implemented to stem these population reductions (Parker et al. 2000, Love et al. 2002, Williams et al. 2010, Yamanaka and Logan 2010). British Columbia (BC) is host to more than 30 species of rockfish (Love et al. 2002). Inshore species (Table 1) aggregate over coastal, rocky environments, which can make them vulnerable to intensive coastal fishing (Parker et al. 2000, Love et al. 2002). Inshore rockfish are also long-lived (from 50 to 120 years) and have a relatively slow maturation rate (Love et al. 2002). Some species take up to 20 years to reach sexual maturity (Table 1), and many species reach market size before reproducing (Love et al. 2002). Additionally, because of their closed (physoclistic) swim bladder, 
Table 1. Life history characteristics of common inshore rockfish species in British Columbia (Love et al. 1991, Frid et al. 2013, Haggarty 2014).

\begin{tabular}{|c|c|c|c|c|c|}
\hline $\begin{array}{l}\text { Common } \\
\text { Name }\end{array}$ & $\begin{array}{l}\text { Scientific } \\
\text { Name }\end{array}$ & Depth Range & $\begin{array}{l}\text { Maximum } \\
\text { Size }\end{array}$ & $\begin{array}{c}\text { Typical } \\
\text { Age }\end{array}$ & Home Range \\
\hline Copper & $\begin{array}{l}\text { Sebastes } \\
\text { caurinus }\end{array}$ & $\begin{array}{l}0-183 \mathrm{~m} \\
\text { (typically } \\
\text { around } \\
90 \mathrm{~m} \text { ) }\end{array}$ & $66 \mathrm{~cm}$ & 50 years & $10 \mathrm{~m}^{2}$ \\
\hline $\begin{array}{l}\text { Quillb- } \\
\text { ack }\end{array}$ & $\begin{array}{l}\text { Sebastes } \\
\text { maliger }\end{array}$ & $\begin{array}{l}0-274 \mathrm{~m} \\
\text { (typically } \\
\text { between } 41-60 \\
\mathrm{~m} \text { ) }\end{array}$ & $61 \mathrm{~cm}$ & 95 years & $\begin{array}{l}\text { Typically less } \\
\text { than } 10 \mathrm{~m}^{2}\end{array}$ \\
\hline Black & $\begin{array}{l}\text { Sebastes } \\
\text { melanops }\end{array}$ & $\begin{array}{l}0-366 \mathrm{~m} \\
\text { (typically at } \\
\text { or above } 55 \\
\mathrm{~m} \text { ) }\end{array}$ & $69 \mathrm{~cm}$ & 50 years & $67 \mathrm{~m}^{2}$ \\
\hline China & $\begin{array}{l}\text { Sebastes } \\
\text { nebulosus }\end{array}$ & $\begin{array}{l}3-128 \mathrm{~m} \\
\text { (typically at } \\
\text { or below } 10 \\
\mathrm{~m} \text { ) }\end{array}$ & $45 \mathrm{~cm}$ & 79 years & $10 \mathrm{~m}^{2}$ or less \\
\hline Tiger & $\begin{array}{l}\text { Sebastes } \\
\text { nigrocinctus }\end{array}$ & $18-298 \mathrm{~m}$ & $61 \mathrm{~cm}$ & $\begin{array}{c}116 \\
\text { years }\end{array}$ & $\begin{array}{l}\text { High site } \\
\text { fidelity }\end{array}$ \\
\hline $\begin{array}{l}\text { Yellow- } \\
\text { eye }\end{array}$ & $\begin{array}{l}\text { Sebastes } \\
\text { ruberrimus }\end{array}$ & $\begin{array}{l}15-549 \mathrm{~m} \\
\text { (typically } \\
\text { between } \\
91-180 \mathrm{~m} \text { ) }\end{array}$ & $91 \mathrm{~cm}$ & $\begin{array}{c}118 \\
\text { years }\end{array}$ & $\begin{array}{l}\text { High site } \\
\text { fidelity }\end{array}$ \\
\hline
\end{tabular}

rockfish suffer severe, often fatal, barotrauma when caught in traps or on lines that are rapidly pulled to the surface (Parker et al. 2006). This makes recreational and commercial catch-andrelease techniques largely ineffective at reducing incidental rockfish mortality (Parker et al. 2000, Yamanaka and Logan 2010). Subsequently, intensive fishing in rocky reef environments can deplete local rockfish populations, making it difficult for species to rebuild even after fishing has stopped (Parker et al. 2000). However, because inshore rockfish are typically sedentary with very small home ranges (Table 1; Love et al. 2002), spatial protection should be highly effective, and indeed has been along the U.S. West Coast, where rockfish conservation areas had significantly larger populations of rockfish and greater species richness than nearby open areas (Keller et al. 2014).

\section{ROCKFISH CONSERVATION AREAS IN BRITISH COLUMBIA}

In the waters of Pacific Canada off the coast of $\mathrm{BC}$, inshore rockfish population declines are a major concern (Yamanaka and Logan 2010, Haggarty 2014). After the creation of an inshore rockfish hook-and-line fishery in the 1970s, stocks began to dramatically decline, with catches peaking in the 1980s and subsequently decreasing (COSEWIC 2009a, 2009b, Yamanaka and Logan 2010, Haggarty 2014). In response to these declines, nongovernment organizations (NGOs) and fishers began lobbying in 2001 for changes to management of inshore rockfish by Fisheries and Oceans Canada (DFO; Yamanaka and Logan 2010). These efforts led to the creation of the Rockfish Conservation Strategy, which identified four goals for enhanced rockfish protection. The strategy aimed to: (1) "account for all catch," (2) "decrease fishing mortality," (3) “establish areas closed
Table 2. Permitted and prohibited commercial and recreational fishing activities within Rockfish Conservation Areas (RCAs). Aboriginal fisheries are not included in the table because their fishing activities are unrestricted within RCAs on account of their constitutional right to harvest (DFO 2014a, Haggarty 2014). Specific species names defined in DFO 2015.

\begin{tabular}{l}
\hline \hline Fishery \\
\hline Activity \\
Permitted Commercial Fisheries \\
Hand picking and diving for invertebrates \\
Prawn and crab trapping \\
Smelt by gillnet \\
Scallop trawling \\
Salmon by seine or gillnet \\
Herring by seine, gillnet, and spawn-on-kelp \\
Sardine by gillnet, seine, and trap \\
Krill by midwater trawl \\
Opal squid by seine \\
Groundfish by midwater trawl \\
Groundfish bottom trawl \\
Groundfish hook and line for halibut, inside rockfish, \\
outside rockfish, lingcod, dogfish \\
Sablefish by trap \\
Salmon trolling \\
Opal squid by hook and line or ring net \\
Shrimp by trawl \\
Hahibited picking of invertebrates \\
Prawn and crab trapping \\
Smelt by gillnet \\
Permitted Recreational Fisheries \\
Groundfish by hook and line \\
Spearfishing \\
Prohibited Recreational Fisheries
\end{tabular}

to all fishing," and (4) "improve stock assessment and monitoring" (Yamanaka and Logan 2010).

In this paper, we focus on the Rockfish Conservation Strategy's spatial component (goal 3: establishing areas closed to all fishing), implemented through Rockfish Conservation Areas (RCAs). Implemented between 2003 and 2007, the RCAs encompass $4847.2 \mathrm{~km}^{2}$ (Haggarty 2014). The RCAs are fisheries closures intended to rebuild rockfish stocks implemented under the Fisheries Act. RCAs lack the permanency that MPA legislation such as the Oceans Act would provide. They are not MPAs, which are intended to conserve and rebuild biological diversity (Robb et al. 2011). The original closed area targets were intended to protect $30 \%$ of rockfish habitat in inside waters, i.e., all waters east of Vancouver Island to the mainland, and $20 \%$ of rockfish habitat in outside waters, i.e., all other Pacific Ocean waters within Canadian jurisdiction. The 164 final RCAs protect $28 \%$ of inside and $15 \%$ of outside rockfish habitat (Yamanaka and Logan 2010). Although RCAs allow some fishing within them (i.e., they are not no-take areas), fishing activities have been significantly reduced to protect inshore rockfish (Table 2; Yamanaka and Logan 2010, Haggarty 2014).

The RCAs were selected based on a public consultation process that included more than 60 coastal community and regional meetings with fishers, NGOs, government officials, and 
Table 3. Design principles as originally created by Ostrom (1990), then modified by Cox et al. (2010) and further reworded for a Rockfish Conservation Area (RCA) analysis.

\begin{tabular}{l}
\hline \hline Ostrom's Original \\
Design Principles \\
\hline 1. Well-defined boundaries: \\
Clearly defined boundaries (effective \\
exclusion of external unentitled parties).
\end{tabular}
provision rules and local conditions: Rules regarding the appropriation and provision of common resources that are adapted to local conditions.
2. Congruence between appropriation and

\begin{tabular}{ll} 
Cox's Modified & Modified RCA \\
Design Principles & Design Principles \\
\hline
\end{tabular}

1a. Clearly defined boundaries: Individuals 1a. Clear user boundaries: Users must clearly or households who have rights to withdraw understand who may utilize the resource and why, i.e., resource units from the common-pool resource (CPR) must be clearly defined. 1b. Clearly defined boundaries: The boundaries of the CPR must be well defined.

2a. Congruence between appropriation and provision rules and local conditions: Appropriation rules restricting time, place, technology, and/or quantity of resource units are related to local conditions.

2b. Congruence between appropriation and provision rules and local conditions: The benefits obtained by users from a $\mathrm{CPR}$, as determined by appropriation rules, are proportional to the amount of inputs required in the form of labor, material, or money, as determined by provision rules.

3. Collective-choice arrangements: Collective- 3. Collective-choice arrangements: Most choice arrangements that allow most resource individuals affected by the operational appropriators to participate in the decision- rules can participate in modifying the making process.

4. Monitoring: Effective monitoring by monitors who are part of or accountable to the appropriators. operational rules. 4a. Monitoring: Monitors are present and actively audit CPR conditions and appropriator behavior.

4b. Monitoring: Monitors are accountable to or are the appropriators.

5. Graduated sanctions: A scale of graduated sanctions for resource appropriators who violate community rules.

6. Conflict-resolution mechanisms: Mechanisms of conflict resolution that are cheap and of easy access.

7. Minimum recognition of rights: Self-determination of the community recognized by higher level authorities

8. Nested enterprises: In the case of larger common-pool resources, organization in the form of multiple layers of nested enterprises, with small local CPRs at the base level.
5. Graduated sanctions: Appropriators who violate operational rules are likely to be assessed graduated sanctions (depending on the seriousness and context of the offense) by other appropriators, officials accountable to these appropriators, or both. 6. Conflict-resolution mechanisms: Appropriators and their officials have rapid access to low-cost local arenas to resolve conflicts among appropriators or between appropriators and officials. 7. Minimal recognition of rights to organize: The rights of appropriators to devise their own institutions are not challenged by external governmental authorities.

8. Nested enterprises: Appropriation, provision, monitoring, enforcement, conflict resolution, and governance activities are organized in multiple layers of nested enterprises. who can fish within RCAs).

1b. Clear resource boundaries: The physical boundaries should be easily visible, e.g., marker buoys and fences, or well defined, e.g., clear signs and maps in prominent locations.

2a. Appropriate resource regulations: Regulations must match local resource conditions. The rules regarding when, how, and where resources can be used or taken must be based on the limitations of the resource itself, e.g., RCAs must be designed to effectively protect rockfish based on habitat and biological characteristics.

2b. Positive cost/benefit perception: Effort expended on resource protection should equal the real and perceived benefits to users and resources, e.g., compliance monitoring in RCAs leads to increased levels of rockfish.

3. Collective choice: Users may participate in rule modification.

4a. Resource monitoring: Monitors are present and actively monitor resource conditions, e.g., monitoring rockfish stocks inside and outside RCAs.

4b. User monitoring: Monitors regulate user behavior and are accountable to or are resource users, e.g., monitoring fishing effort within RCAs.

5. Graduated sanctions: The severity of penalties must match the severity of violations: resource users who violate operational rules are assessed graduated sanctions by socially accountable monitors.

6. Access to conflict resolution: Resource users and monitors have easy access to low-cost methods of resolving conflicts among users or between users and monitors.

7. Rights to organize: Ability to organize local, smallscale governance groups: the rights of resource users to create their own rules are not challenged by external governmental authorities.

8. Nested governance: Multiple, nested governance groups from small-scale to large-scale manage all aspects of the SES. 
community groups. The selection of RCA locations was based upon reported rockfish habitat, the needs of local stakeholders, and a combination of bathymetry and fisheries data used to identify rockfish habitat (Yamanaka and Logan 2010).

The purpose of this paper is to assess the performance of RCAs, which have been in place for approximately a decade (from 7 to 11 years), and provide recommendations for improvements. We used the design principles highlighted by Ostrom (1990) as key aspects of sustainable resource management to assess the ecological and social performance of RCAs based on studies conducted to date. RCAs are faced with many of the same issues as other fisheries closures and marine conservation areas are (e.g., social buy-in, compliance, enforcement, monitoring); hence, their assessment has the potential to provide lessons for current and future marine conservation areas. Additionally, we assess the usefulness and applicability of scaling up the design principles for federally managed resource systems.

\section{METHODS}

We used Ostrom's design principles (Ostrom 1990), as redefined by Cox et al. (2010), as a framework to assess effectiveness of RCAs. We reworded the design principles to make them accessible and directly applicable to RCAs (Table 3), and assessed them for two rockfish fisheries: commercial and recreational. The aboriginal fishing sector is also a significant user of rockfish; however, because of their constitutional right to harvest, DFO chose not to restrict their access to fishing within RCAs and, as such, their actions are not governed by RCA regulations (Haggarty 2014). A design principle analysis of the aboriginal fishery would, therefore, not be applicable in most cases. Additionally, information on aboriginal fishing habits within RCAs is largely unavailable. However, the aboriginal fishery is mentioned throughout the analysis when applicable information was available.

The commercial fishery within BC consists of many different sectors (Table 4). Many of these sectors are affected by RCA regulations to varying degrees and are held accountable under groundfish integration regulations and the Rockfish Conservation Strategy (Davis 2008, Yamanaka and Logan 2010). For the purposes of our paper the sectors that are impacted by RCA regulations (Table 4) are assessed as one fishery and hereafter referred to as the commercial fishery. RCAs also impact many other nonfishing stakeholders including nonconsumptive users like scuba divers and boaters and the environmental sector, which has an interest in protecting and rebuilding ecosystems and biodiversity. However, we only assessed the relative presence and absence of the design principles for recreational and commercial fisheries because RCAs are fisheries closures and there is a lack of information on RCA impacts on nonconsumptive sectors.

An analysis of the extent to which RCAs meet the design principles allowed us to highlight current strengths and weaknesses of this conservation system approximately a decade after implementation. We also could assess the applicability of the design principles for a federally designated conservation system.

We conducted a thorough review of existing RCA literature to assess RCA social and ecological effectiveness to date, and look for evidence of the key elements of the design principles (Table 5, Appendix 1). Each design principle was broken down into its key elements. We then rated RCAs on a four-point scale to evaluate the relative presence or absence of each design principle (Table 6 , Appendix 2). Rankings were based on the following definitions: "present" indicates that all elements of the design principle's definition have been met; "moderately present," that the majority of the design principle's definition has been met, although some elements could be improved; "lacking," that the majority of the design principle's definition has not been met, with few elements of the principle reflected in the management system; and "absent," that no elements of the design principle's definition have been met. Scores were based on both the number of design principle elements reflected in each fishery sector and the extent to which those elements were present. For example, all three elements of design principle 2 a (appropriate resource regulations) were present to some degree in the recreational and commercial sectors; however, all of these elements could be improved or enhanced. As such, both the commercial and recreational fisheries score for design principle $2 \mathrm{a}$ was moderately present. A more thorough example of this ranking process can be found in Appendix 2. For the purposes of this report, we systematically evaluated the recreational and commercial fishing sectors to provide recommendations for improving RCA effectiveness.

Table 4. This table lists the commercial fishery sectors (by target species) in British Columbia and the gear types each fishery uses. Specific species names defined in DFO 2015.

\begin{tabular}{ll}
\hline \hline $\begin{array}{l}\text { Commercial Fishery Sector } \\
\text { (by target species) }\end{array}$ & Gear Type \\
\hline $\begin{array}{l}\text { Dogfish } \\
\text { Lingcod }\end{array}$ & ${ }^{\dagger}$ Long Line, ${ }^{\dagger}$ Hook and Line \\
Rockfish (Inside waters) & ${ }^{\dagger}$ Hook and Line \\
Rockfish (Outside waters) & ${ }^{\dagger}$ Hook and Line \\
Groundfish & ${ }^{\dagger}$ Bottom Trawe \\
Halibut & ${ }^{\dagger}$ Long Line, ${ }^{\dagger}$ Hook and Line \\
Sablefish & ${ }^{\dagger}$ Long Line, ${ }^{\dagger}$ Trap \\
Salmon & Seine, Gillnet, ${ }^{\dagger}$ Trolling \\
Herring & Seine, Gillnet, Spawn on Kelp \\
Sardine & Seine, Gillnet, Trap \\
Krill & Mid-water Trawl \\
Opal Squid & ${ }^{\dagger}$ Hook and Line, ${ }^{\dagger}$ Ring Net, Seine \\
Invertebrates & Hand picking, Diving \\
Prawn/Crab & Trap \\
Smelt & Gillnet \\
Scallop & Trawl \\
Shrimp & Trawl \\
\hline
\end{tabular}

The use of these gear types is prohibited in Rockfish Conservation Areas (Davis 2008, Haggarty 2014).

\section{RESULTS}

\section{Summary of ecological effectiveness}

RCAs have now existed in BC for approximately a decade. Although there is currently no formal strategy for monitoring the impacts of RCAs on rebuilding rockfish populations, a variety of independent studies have attempted to evaluate the performance of RCAs (Table 5, Appendix 1; Marliave and Challenger 2009, Cloutier 2010, Chalifour 2012, Haggarty 2014). These studies were limited by a lack of historic baseline data. Therefore, they primarily used a control-impact model, whereby sites within RCAs were compared with nearby unprotected sites (Haggarty 
Table 5. Summary of the key literature on social and ecological impacts of Rockfish Conservation Areas (RCAs). See Appendix 1 for a more in-depth summary.

\begin{tabular}{lll}
\hline \hline Key RCA Literature & Ecological Summary & Social Summary \\
\hline $\begin{array}{l}\text { Yamanaka and } \\
\text { Logan (2010) }\end{array}$ & $\begin{array}{l}\text { RCA Site Selection: Fisheries consultations and bathymetry } \\
\text { data were used to locate likely rockfish habitat. }\end{array}$ & $\begin{array}{l}\text { Collective Choice: Extensive consultations with fishers, } \\
\text { community members, and NGOs prior to RCA site selection. }\end{array}$ \\
& $\begin{array}{l}\text { Commercial Fishers: The Rockfish Conservation Strategy } \\
\text { (implemented in tandem with Groundfish integration) }\end{array}$ \\
significantly altered commercial groundfish fishing practices. \\
Haggarty (2014) & $\begin{array}{l}\text { Remote Operated Vehicle (ROV) Survey Results: No } \\
\text { statistically significant reserve response. Mean inshore } \\
\text { rockfish density higher inside than outside RCAs. }\end{array}$ & $\begin{array}{l}\text { Recreational Fishers: Many recreational fishers do not know } \\
\text { about RCAs or do not know who can fish in them. Tension } \\
\text { between recreational fishers and aboriginal fishers who are } \\
\text { permitted to fish within RCAs as a traditional harvesting } \\
\text { right. Recreational fishing compliance was found to be low in } \\
\text { some RCAs. }\end{array}$
\end{tabular}
RCA in the Broken Islands Group as compared to other locations within Barkley Sound.

Marliave and Challenger (2009)

Cloutier (2010)

Chalifour (2012)
Scuba Survey Results: No reserve effect. Reserve effect not expected as the RCAs were newly established. Intended to serve as baseline data for future assessments of RCA effectiveness.

Side-Scan Sonar Results: Rockfish are strongly associated with piled boulder habitats not easily detected by original bathymetry data.

Scuba Survey Results: RCAs had an average of 1.6 times more rockfish than unprotected sites. No correlation between rockfish density and age of RCAs.

Scuba Survey Results: Rockfish density higher outside the RCAs, however, habitat variability was not considered in the research design, which could impact results. Some RCAs are located in unsuitable rockfish habitat.
Commercial Fishers: Supportive of RCAs but not their expansion. Understand that RCAs offer the chance for "spillover" benefits, which could improve future fishing activities. Concern over recreational fisher behavior and a perceived lack of compliance to RCA regulations.

\begin{abstract}
Aboriginal Fishers: Supportive of RCAs as an ecological insurance policy. Feel they were not consulted, or not adequately consulted during RCA creation. Some feel that fishing pressure has decreased in RCAs, some feel that recreational fishing remains unchanged. Some fishers feel a pressure not to fish in RCAs despite their constitutional right. They desire better information on RCA effectiveness and education for other sectors on First Nations right to harvest. Collective Choice: RCA selection influenced by needs/desires of fishing sectors. Occasionally resulted in the protection of suboptimal rockfish habitat.
\end{abstract}

\section{Not Applicable}

Recreational Fishers: Lack of RCA boundary/regulation knowledge can lead to tension between monitors and users.
2014). This can be an effective tool for assessing response within protected areas and is commonly used for marine conservation areas (Claudet et al. 2008, Claudet and Guidetti 2010). However, given the variety of new fisheries management initiatives developed over the past years in $\mathrm{BC}$, including the integration of all commercial groundfish fisheries, significant reductions in Total Allowable Catch quotas for commercial inshore rockfish, and the creation of RCAs, it is difficult to isolate the impacts of each of these initiatives on rockfish populations. The confounding effects of these different management measures could make the control-impact method of studying RCA response less effective (Haggarty 2014).

Most of the studies to date did not show significant statistical differences in rockfish densities within RCAs compared with areas outside RCAs. For example, Remotely Operated Vehicle surveys did not report a statistically significant reserve response, although there was a slight trend toward higher mean rockfish density within RCAs (Haggarty 2014). In contrast, another study surveyed 15 different locations throughout the Strait of Georgia and found that RCAs had, on average, 1.6 times more rockfish than nearby unprotected sites (Cloutier 2010). Although there is some evidence to suggest that RCAs are beginning to rebuild rockfish stocks (Cloutier 2010, Haggarty 2014), at this stage the ecological results are largely inconclusive. This could be partly because of the relative infancy of the RCAs given the long-lived nature of rockfish. Additionally, the lack of a consistent monitoring program makes it difficult to control for variability and compare data across studies.

\section{Summary of social effectiveness}

Information on the social impacts of RCAs is still minimal, with only one published study to date examining fisher support for RCAs (Table 5, Appendix 1). Haggarty (2014) found that both 
Table 6. Analysis of relative presence or absence of the design principles in the structure of British Columbia's network of Rockfish Conservation Areas (RCAs).

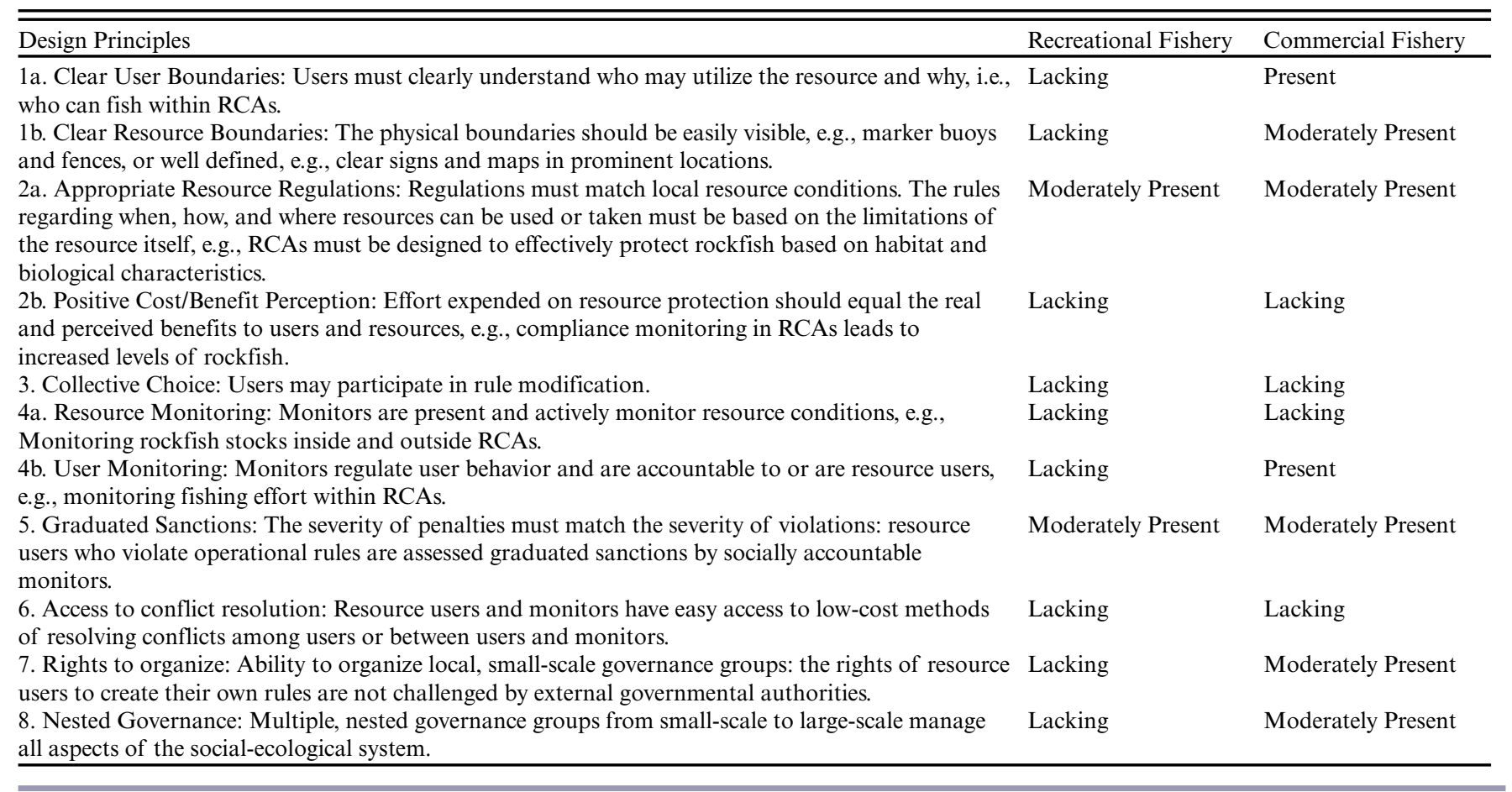

the recreational and commercial fishing sectors were supportive of RCAs, although both groups commented on the lack of empirical evidence indicating that RCAs are an effective conservation tool. Both sectors were reluctant to fully support the RCAs or any future expansion until scientific evidence could evaluate the contribution of RCAs to the rebuilding of rockfish stocks. The commercial sector expressed concern over a perceived lack of recreational fisher compliance with RCA regulations, which could be significantly impacting the ability of RCAs to protect rockfish stocks. Aerial flyover data analyzed by Haggarty (2014) supports the commercial sector's perception of noncompliance, and recreational fishing levels appear to be nearly unchanged within RCAs. Similarly, the recreational fishing sector expressed concern over the ability of aboriginal fishers to practice their traditional right to harvest within RCAs. Aboriginal fishers were generally unhappy with their perceived lack of consultation in the RCA development process and the lack of fisher understanding of their traditional rights to harvest (Haggarty 2014). Overall, despite the recreational fishery's support of RCAs, there is a lack of understanding and awareness of RCA goals and regulations. Additionally, there are high levels of tension and distrust among the different fishing sectors regarding RCA regulations and compliance (Haggarty 2014).

As yet, no information exists about other social impacts of RCAs. It is not known whether RCAs negatively affected livelihoods of commercial fishers, or whether they have substantially impacted enjoyment of fishing by recreational fishers. Furthermore, RCAs have the potential to affect nonfishing populations such as recreational boaters, property owners, NGOs, and many other organizations who may have a vested interest in protecting marine ecosystems for aesthetic, touristic, and economic reasons. To date, there are no studies on the impacts of RCAs on nonfishing communities.

\section{DESIGN PRINCIPLE ANALYSIS OF RCAS}

We assessed the performance of RCAs by using the design principles (Ostrom 1990, Cox et al. 2010). Some design principles are not as relevant as others because RCAs are a federally managed system, not a community-based initiative. However, for the purposes of this assessment, they have been included in the analysis because they can be useful for highlighting the challenges and weaknesses of federally managed systems. Design principles that are less applicable on a federal scale have been marked with a dagger ( $\dagger$ ). The problems they present are discussed in more detail in the Discussion section.

\section{1a. Clear user boundaries: Users must clearly understand who} may utilize the resource and why (i.e., who can fish within RCAs) The recreational fishing sector lacks a strong understanding of user boundaries (Haggarty 2014). Although RCA regulations clearly state what activities are permitted in these closed areas (Table 2) and it is the responsibility of recreational fishers to learn and understand these rules, RCA regulations do not explicitly list which fishing activities are prohibited. In a recent study with more than 300 fishers, this was consistently mentioned as a source of confusion about RCA regulations (D. Lancaster, P. Dearden, and N. C. Ban, unpublished manuscript). This lack of specificity means that recreational salmon or halibut fishers may believe that fishing within RCAs is permitted (Cloutier 2010, Chalifour 2012, Haggarty 2014; D. Lancaster, P. Dearden, and N. C. Ban, unpublished manuscript). Additionally, recreational fishers 
expressed concern over aboriginal fishers' traditional right to harvest within RCAs (Haggarty 2014).

Commercial fishers are informed of fisheries regulations, including spatial restrictions, by DFO and fishery associations such as the Canadian Groundfish Research and Conservation Society (CGRCS; Davis 2008, CGRCS 2010, Haggarty 2014). The existence of $100 \%$ at-sea observation in the trawl fishery and electronic monitoring via global positioning systems (GPSs) in the hook-and-line fishery emphasizes the importance of following regulations within RCAs (Haggarty 2014).

1b. Clear resource boundaries: The physical boundaries should be easily visible (e.g., marker buoys, fences) or well defined (e.g., clear signs and maps in prominent locations).

It is the responsibility of recreational fishers to learn and understanding recreational resource extraction rules. However, despite this responsibility, recreational knowledge of RCA regulations is low, there is little DFO enforcement of regulations on the water, and many recreational fishers find DFO regulations hard to understand and difficult to access (Haggarty 2014; D. Lancaster, P. Dearden, and N. C. Ban, unpublished manuscript). Thus, the recreational fishing sector lacks clear resource boundaries for RCAs (Chalifour 2012, Haggarty 2014). RCA boundaries are clearly and strictly defined online using GPS coordinates, landmarks, and charts (DFO 2014a). However, hard copy versions of these closed areas are difficult to obtain (Chalifour 2012, Haggarty 2014). There are very few highly visible charts in prominent locations such as boat launches and marinas (Chalifour 2012, Haggarty 2014). There are also no physical markers or reminders of RCA boundaries on the water. The impracticality of placing physical markers and signs in a marine environment makes it impossible for fishers to know if they are within one of these closed areas unless they had previous knowledge of their existence (D. Lancaster, P. Dearden, and N. C. Ban, unpublished manuscript).

Intensive monitoring of the commercial fishery makes adhering to RCA boundary restrictions essential to commercial success (design principle 4b; Yamanaka and Logan 2010, Haggarty 2014). All commercial fishing boats are equipped with GPS tracking and onboard/video observers, and as such, any unauthorized entrance of commercial vessels into closed RCAs can be reported and penalized (F. Snelgrove, personal communication, October 14, 2014). It is still the responsibility of commercial vessels to input RCA boundaries manually into navigation software. However, to avoid penalty, most commercial fishers take measures to ensure they do not accidentally enter into RCAs (CGRCS 2010).

2a. Appropriate resource regulations: Regulations must match local resource conditions. The rules regarding when, how, and where resources can be used or taken must be based on the limitations of the resource itself (e.g., RCAs must be designed to effectively protect rockfish based on habitat and biological characteristics).

Appropriate resource regulations are moderately present in both the recreational and commercial fishing sectors (Marliave and Challenger 2009, Cloutier 2010, Favaro et al. 2010, Yamanaka and Logan 2010, Chalifour 2012, Haggarty 2014). The majority of activities permitted within the RCAs do not negatively affect inshore rockfish populations (Yamanaka and Logan 2010, Haggarty 2014). However, there is evidence to suggest that prawn (e.g., genus Pandalus) trapping within RCAs could cause significant rockfish bycatch, because rockfish are often found in recovered prawn traps (Favaro et al. 2010). Additionally, prawns are a key food source for rockfish, and the continued removal of their prey from RCAs could limit rockfish recovery (Cloutier 2010, Haggarty 2014). Conversely, reducing prawn densities could also cause trophic cascades if rockfish begin to intensively target other species (Cloutier 2010). However, recent research within RCAs did not find a significant trend towards rockfish-induced trophic cascades (Cloutier 2010).

Although the RCAs were not designed as a network, research has shown that their current placement could promote important larval recruitment between protected areas and create spillover effects (Lotterhos et al. 2014). More research is necessary to test whether RCAs are adequately positioned to maximize this network effect (Gaines et al. 2010a, 2010b, Haggarty 2014, Lotterhos et al. 2014). There is also some evidence to suggest that the bathymetry data used to inform RCA site selection was not detailed enough to locate optimal rockfish habitat (Marliave and Challenger 2009). This means some RCAs may be protecting suboptimal rockfish habitat, while other key rockfish habitats may be unprotected (Marliave and Challenger 2009, Chalifour 2012).

2b. Positive cost/benefit perception: Effort expended on resource protection should equal the real and perceived benefits to users and resources (e.g., compliance monitoring in RCAs leads to increased levels of rockfish).

Positive cost/benefit perception is lacking in the recreational sector (Haggarty 2014). Without empirical data to illustrate that RCAs are helping to rebuild rockfish stocks or provide spillover benefits to fishers (see design principle 4a; Gaines et al. 2010a, $2010 b$ ), many recreational fishers are currently reluctant to fully support RCAs (Haggarty 2014). Additionally, many recreational fishers have expressed their concern over a lack of enforcement of RCA regulations (D. Lancaster, P. Dearden, and N. C. Ban, unpublished manuscript). Although the majority of recreational fishers surveyed currently support the idea of RCAs (Haggarty 2014), a perceived lack of enforcement and data to measure RCA effectiveness makes it difficult for fishers to assess the cost/benefit of maintaining RCAs.

Cost/benefit perception is similarly lacking in the commercial sector, with a dearth of empirical data again making it difficult for commercial fishers to assess the ability of RCAs to rebuild rockfish stocks and provide spillover benefits to fishers (Haggarty 2014). Additionally, the fact that RCAs were implemented in tandem with rockfish catch restrictions in the commercial fishery makes it difficult to determine the cause of changes within rockfish populations (Haggarty 2014).

†3. Collective choice: Users may participate in rule modification. Collective choice arrangements within the recreational fishery are currently lacking (Davis 2008). The recreational fishery was actively included in consultation during RCA creation and site selection, although final RCA selection rested with DFO (Davis 2008, Granek et al. 2008, Yamanaka and Logan 2010). Since final implementation, RCAs have not been reopened for amendments (Davis 2008). Additionally, with Canadian fisheries being federally managed (Davis 2008, Yamanaka and Logan 2010), RCAs are not currently designed to be comanaged by the users, i.e., fishers. 
Collective choice arrangements are also lacking in the commercial sector (Davis 2008). Like the recreational sector, commercial fishers were actively consulted during RCA creation (Yamanaka and Logan 2010). The Commercial Industry Caucus (CIC), which represents members from all groundfish fishing sectors as well as DFO and provincial representatives, still holds meetings to refine the groundfish Integrated Fisheries Management Plan (Davis 2008). Although the CIC, which is a consensus-based decisionmaking group, cannot directly modify RCA regulations, they can propose significant changes to the groundfish integration plan, which can impact BC's rockfish stocks. DFO has also worked with commercial, recreational, and First Nations fishers on various other adaptive management projects like the Pacific North Coast Integrated Management Area and coral and sponge reef closures (DFO 2013). However, as in the recreational sector, commercial fishers have been unable to modify RCA regulations since implementation (Haggarty 2014).

\section{4a. Resource monitoring: Monitors are present and actively monitor resource conditions (e.g., monitoring rockfish stocks inside and outside RCAs).}

Resource monitoring was ranked as lacking because there is currently no RCA monitoring plan, either federally or independently organized by fishing sectors or independent organizations such as NGOs (Haggarty 2014). Although independent research has been ongoing (Marliave and Challenger 2009, Cloutier 2010, Chalifour 2012, Haggarty 2014), the lack of consistency among studies makes it difficult to compare data. Additionally, RCAs were implemented without determining baseline rockfish populations, which makes it difficult to determine if there is a significant reserve effect in RCAs (Marliave and Challenger 2009, Haggarty 2014). DFO did partner with academic scientists to survey RCAs using Remotely Operated Vehicles; however results are pending and no follow-up surveys are planned (Haggarty 2014).

\section{4b. User monitoring: Monitors regulate user behavior and are accountable to or are resource users (e.g., monitoring fishing effort within RCAs).}

Monitoring of the recreational fishing sector is generally lacking, although the amount of enforcement varies by area (Haggarty 2014). A recent study using DFO aerial survey data found that recreational fishing within RCAs has remained primarily unchanged since implementation, with some RCAs showing increased fishing effort over time (Haggarty 2014). This could be because of a lack of DFO monitoring in many of these areas (Haggarty 2014).

The commercial fishing sector is extensively monitored for fisheries violations (Yamanaka and Logan 2010, Haggarty 2014); $100 \%$ electronic or onboard observer/video monitoring ensures that commercial violations of RCA boundaries will be noted and penalized (Haggarty 2014). As such, commercial compliance to RCA regulations is known to be high (Haggarty 2014). Additionally, DFO officers are accountable to both recreational and commercial users in the same way as police officers. Disputes between users and monitors can be addressed through the Canadian court system (see design principle 5; F. Snelgrove, personal communication, October 14, 2014). The monitoring of the commercial sector is an example of excellent user monitoring where the monitors are not the users themselves.
5. Graduated sanctions: The severity of penalties must match the severity of violations: resource users who violate operational rules are assessed graduated sanctions by socially accountable

monitors.

Graduated sanctioning is moderately present within the recreational fishery (Government of Canada 2014a). All official sanctions are handled by DFO fishery officers. According to BC Sport Fishing Regulations (a subsection of the Fisheries Act), recreational violations of RCA rules are subject to a $\$ 250$ fine (Government of Canada 2014b). However, DFO officers may also issue a verbal or written warning, or provide educational materials in place of a voluntary penalty ticket (tickets are issued at the discretion of DFO officers on a case-by-case basis; F. Snelgrove, personal communication, October 14, 2014). Once issued, these sanctions are under the jurisdiction of the Canadian Criminal Code (Government of Canada 2014c). However, because of the lack of user monitoring (see design principle $4 \mathrm{~b}$ ), sanctions are rare and some recreational fishers have stated that officers typically issue warnings instead of penalties (D. Lancaster, P. Dearden, and N. C. Ban, unpublished manuscript).

Sanctioning within the commercial sector is moderately present (Government of Canada 2014a). As in the recreational sector, the severity of sanctions is left to the discretion of DFO officers and varies for each offence (F. Snelgrove, personal communication, October 14, 2014). The high level of commercial compliance because of intensive monitoring means commercial sanctioning is rare (Haggarty 2014). Information on the perceived appropriateness of commercial graduated sanctions was not available. As such, this design principle was listed as moderately present because all other aspect of the definition were met.

${ }^{\dagger}$ 6. Access to conflict resolution: Resource users and monitors have easy access to low-cost methods of resolving conflicts among users or between users and monitors.

Conflict resolution mechanisms are lacking within the recreational fishing sector (F. Snelgrove, personal communication, October 14, 2014). All Canadian citizens have access to the court system to resolve conflicts. However, entering disputes into the court system is not regarded as a particularly easy or low-cost method of resolving conflicts. All formal user-to-user or user-tomonitor disputes (e.g., contesting a voluntary penalty ticket) must utilize the court system. Research has shown that when conflict resolution mechanisms are not easily accessible, the management of common-pool resources can be difficult (Cox et al. 2010).

The commercial sector's conflict resolution mechanisms were also ranked as lacking (IPHC 2014). As described above, fishery violations can be contested in the Canadian court system. Because DFO is a federally run system, disputes between commercial fishers and DFO officials can be appropriately and officially addressed in court. Additionally, the International Pacific Halibut Commission (IPHC), an independent international organization designed to advise federal and state fisheries managers, acts as a platform for conflict resolution between all halibut fishery sectors, i.e., commercial, recreational, and aboriginal, from both Canada and the United States. Halibut fishers are also subject to rockfish catch restrictions through the groundfish Integrated Fisheries Management Plan. Any conflicts between these user groups, RCA related or otherwise, can be addressed at the annual meeting of the conference board. However, as an advisory body, the IPHC 
has no official power to resolve conflicts and acts as a discussion platform rather than a formal conflict resolution mechanism (IPHC 2014).

\section{${ }^{\dagger}$ 7. Rights to organize: Ability to organize local, small-scale governance groups; the rights of resource users to create their own rules are not challenged by external governmental authorities.}

The right to create rules is lacking in the recreational fishery (Davis 2008). All fishers and community members have the right to create independent fishery-related groups. The Sport Fish Advisory Board (SFAB) is a long-standing example of one of these groups. The SFAB played a large role in the selection of RCA sites (DFO 2014b). However, neither the SFAB nor any other independent fishery organization has the right to officially modify RCA rules or regulations (see design principle 3). They do, however, have the right to lobby DFO for changes and make recommendations. Nevertheless, a recently interviewed SFAB member expressed disappointment when DFO ignored a request for an RCA boundary change (Haggarty 2014). This lack of official, independent decision-making power is indicative of a federally run common-pool resource as opposed to a community-based resource management regime (Cox et al. 2010). However, despite the federally run structure of Canadian recreational fisheries, there is still a high level of independent organization and community consultation (Davis 2008, Yamanaka and Logan 2010).

The commercial fishery's right to organize is moderately present (Davis 2008, Haggarty 2014). As discussed in design principle 3 (collective choice), commercial groundfish fisheries have established independent organizations that meet regularly as part of the CIC to suggest revisions to the groundfish Integrated Fisheries Management Plan. The impact of this plan on rockfish fishing is significant (Davis 2008, Yamanaka and Logan 2010). However, commercial fishers do not have the ability to modify RCA regulations at this time and may only propose changes through independent group lobbying. The SFAB also has the capacity to lobby and propose changes; however, it does not offer full membership to recreational fishers in the way all commercial fishery license holders hold formal membership in at least one fishery organization (Davis 2008, DFO 2014b). This makes it difficult for SFAB representatives to accurately present the different interests of the entire recreational fishing sector. Design principle 7 (rights to organize) and design principle 8 (nested governance; see the following section) were ranked as moderately present for the commercial sector and lacking for the recreational sector.

$\dagger$ 8. Nested governance: Multiple, nested governance groups, from small-scale to large-scale, manage all aspects of the socialecological system.

Nested governance within the recreational fishing sector is lacking (Davis 2008). The Canadian recreational fishery is federally managed; thus, the SFAB has the ability to lobby for changes to recreational fishing regulations, but not to manage or monitor recreational fishers. Recreational fishers are able to suggest changes to current management schemes through the annual meeting of the conference board for the IPHC (IPHC 2014). However, without a strong DFO presence on the water (Haggarty 2014), this lack of community-based monitoring could lead to low compliance. For example, a Victoria-based angling association representative described a case where a member was removed from their club after repeated violation of fisheries laws. However, despite his removal from the angling association, the offending individual was able to continue fishing independently and eventually joined a different fishing association in the region. Cases like this highlight how community-based governance could have an important role in fisheries management. For example, if angling association membership were mandatory and these regional groups were granted the authority to revoke licenses, this offending fisher could have been penalized by other local fishers who understood his offences and how they affected their shared resources.

Nested governance in the commercial fishery is moderately present (Davis 2008, CGRCS 2010, IPHC 2014). A moderate level of collaborative management is achieved through organizations like the CIC, IPHC, and CGRCS. These organizations assist in the management of the commercial fishery through stock assessments, annual meetings, and yearly regulatory suggestions (Davis 2008, CGRCS 2010, IPHC 2014). However, these independent organizations act only as advisory bodies, with the official decision-making power resting at the federal level (Davis 2008). Nevertheless, the involvement of the commercial sector in the decision-making process is extensive and constitutes a significant level of informal nested governance.

\section{DISCUSSION AND CONCLUSION}

RCAs in BC are currently struggling to attain maximum social and ecological success. Some ecological studies suggest that RCAs are having a positive impact on rockfish populations within protected area boundaries (Cloutier 2010); however, the majority of studies are currently inconclusive. When compared with the ecological success of RCAs created in 2002 on the U.S. West Coast (Keller et al. 2014), Canadian RCAs have considerable room for improvement. Research is required to understand the differences in the ecological success of RCAs in each country, but the management challenges we address in this paper may play a role in the limited success of Canadian RCAs to date. Although there is a dearth of information on the social impacts of RCAs, existing research suggests that there is tension between fishing sectors, a desire for ecological data on RCA impacts, a lack of recreational fisher understanding of RCA regulations, and a potential problem with low compliance in the recreational fishing sector (Haggarty 2014).

We used an analysis of design principles to identify areas of improvement for RCA management. Although the design principles are not meant to be a panacea or checklist (Ostrom 1990), they nevertheless point to suggestions for improved management. We identified eight key recommendations. Many of our recommendations for RCA improvement are also identified by Haggarty (2014), highlighting the importance of these suggestions.

First, managers should clarify social and ecological boundaries. Although it is the responsibility of fishers to understand resource extraction regulations, low knowledge among recreational fishers suggests that more accessible information is necessary or more education on the importance of learning regulations is required. User boundaries (design principle 1a) can be clarified through a public education and outreach campaign and facilitated meetings 
with fisheries representatives from the commercial, recreational, and aboriginal sectors. This education campaign should not only address why some gear types are prohibited, but also explain RCA goals, regulations, and why rockfish need protection. Resource boundaries (design principle 1b) can be clarified through prominent posting of local RCA locations at boat launches and marinas in tandem with increased awareness of RCAs through public outreach (D. Lancaster, P. Dearden, and N. C. Ban, unpublished manuscript). Additionally, a popular recommendation from recreational fishers (D. Lancaster, P. Dearden, and N. C. Ban, unpublished manuscript) is to place physical marker buoys or highly visible signs on the water in areas of high fishing effort. However, implementing this recommendation is challenging because many RCAs are in navigable waters, and buoys could be navigation hazards. Shoreline markers, similar to boundary signs demarking fishery areas, could be implemented where possible. More feasibly, boundaries could be clarified through the creation of electronic maps (e.g. an App for smartphones) and posting maps with RCA boundaries at docks and marinas.

Second, resource regulations (design principle 2a) should be reassessed to determine if activities such as prawn trapping are detrimental to rockfish populations and should be prohibited. The cost/benefit of making RCAs fully no-take areas should also be considered. Additionally, an assessment of rockfish habitat quality within RCAs should be conducted and amendments made where necessary to protect the most important habitats for inshore rockfish.

Third, to improve cost/benefit perceptions (design principle $2 \mathrm{~b}$ ), resource and user monitoring (design principles $4 \mathrm{a}$ and $4 \mathrm{~b}$ ) should be increased. Improving resource and user monitoring would give managers the important social and ecological information necessary to create social buy-in, which is essential to positive cost/benefit perceptions. This information could be presented as part of the previously mentioned outreach campaign. Members from each fishing sector expressed an acute interest in the current status of rockfish stocks and the ecological impacts of RCAs. A consistent resource monitoring program should be developed to assess current rockfish densities within RCAs and measure the changes and patterns that occur over time (Haggarty 2014). This information is extremely important for assessing the effectiveness of RCAs and will allow researchers to offer fishers and the general public more concrete answers about the status of current rockfish populations. Furthermore, DFO user monitoring of the recreational fishing sector should be implemented to prevent noncompliance that could be significantly impacting the ability of rockfish populations to rebuild, especially within the Strait of Georgia. Monitoring plays an important role in compliance, with more heavily patrolled areas showing lower levels of fishing effort than relatively unpatrolled locations (Haggarty 2014). As such, if DFO does not have sufficient funds to monitor RCAs, local stewardship committees could be organized to voluntarily monitor RCAs and report illegal activities. Many First Nations groups have already created a coastal guardian watchmen network along much of the central coast of $\mathrm{BC}$ to monitor sustainable practices throughout their territories (Coastal Stewardship Network, http://coastalguardianwatchmen.ca). Similar volunteer programs should be considered along the coast of BC, and DFO should offer funding and/or training for these programs wherever possible.
Fourth, although collective choice agreements (design principle 3 ) are less applicable in a federally run resource management system, DFO should consider initiating a regular 10-year review program beginning now, approximately a decade after implementation, to address the concerns of all user groups and make revisions to RCA regulations as necessary. In this way, collective choice could be scaled up to a federal system that still maintains a top-down approach but offers stakeholders the opportunity to amend these regulations on a decadal cycle. This review process should also include local scientists and NGO representatives who can offer important information and suggestions on regional ecological and social challenges and concerns.

Fifth, graduated sanctions (design principle 5) should be reassessed after gathering data on recreational fisher compliance. If noncompliance is a significant problem in RCAs, DFO should encourage harsher sanctioning systems to discourage illegal fishing activities in these closed areas. Similarly, a review of commercial sanctioning should assess whether current penalties are appropriate.

Sixth, easy access to conflict resolution (design principle 6) is a challenge for federally run systems that rely on the court system to handle disputes. Although the court system is an appropriate tool for user-to-monitor conflicts in a federally run fisheries system, it would be valuable, in an ideal scenario, to create a community-based group to address disputes between fishers and between different fishing sectors (e.g., recreational versus aboriginal or recreational versus commercial). Such a group could utilize professional facilitators and consensus decision making to resolve minor disputes and provide more accessible conflict resolution. This kind of community-based conflict resolution could be a first step toward promoting better communication and relieving decades of tension between these typically disconnected groups (Davis 2008, O'Connell 2012, Dedual et al. 2013).

Seventh, the rights to organize (design principle 7) could be improved. This is a difficult principle to scale up to a federal level. Nevertheless, the fact that the CIC exists and successfully developed a DFO-approved groundfish integration plan through consensus decision making suggests that a similar committee could be organized to review RCAs. DFO should consider creating an official RCA collaborative fisheries planning committee, not unlike the CIC, with representatives from commercial, recreational, and aboriginal sectors as well as community groups, NGOs, and academics. This group could serve as an independent organization to monitor and reassess RCAs periodically for both social and ecological effectiveness. Although the tensions between these different groups often originates from outside of the realm of RCA management (Davis 2008, O'Connell 2012), an official RCA collaborative committee in combination with better conflict resolution could start a valuable shift toward communication and collaboration between these groups (Dedual et al. 2013).

Eighth, nested governance (design principle 8) could be improved. The commercial fishery maintains a certain level of nested governance through organizations like the CIC and IPHC, while the recreational fishery has very little power to self-regulate on a local scale, which can make it difficult to locate and stop problem fishers who may be consistently violating regulations. If angling 
associations were granted the authority to revoke fishing licenses, not unlike the recreational fishery in Scotland (UK Government 2014), and recreational fishers were required to maintain a membership, then angling organizations could self-regulate within the bounds set by the federal management agency. In the absence of funds for intensive DFO enforcement, community groups such as angling associations could take on the role of monitoring local users. Although this proposal would be complex to implement and is not immune to corruption, it warrants future consideration by the SFAB and DFO as a big picture idea.

Although we highlight many challenges, the RCAs were implemented rapidly and accounted for the diverse needs of many groups. As such, they serve as an excellent and rare example of immediate, consultation-based action to protect a threatened population. RCA managers should continue in the same inclusive and timely style and reassess these conservation areas to ensure they adequately protect both resources and user needs.

\section{Challenges to scaling up design principles for a federal resource management system}

The design principle assessment of the RCAs effectively highlighted areas for improvement. However, certain design principles were less applicable to a federally run system than the community-managed areas from which they originated (Ostrom 1990). In particular, design principle 3 (collective choice), is less applicable to a federally managed common-pool resource because management structure was not designed with ongoing, participatory rule modification in mind. Nevertheless, the RCAs were created through an extensive consultation process, and this design principle highlights how a 10 -year review process could periodically incorporate collective choice even in a federally run system. Similarly, design principle 7 (rights to organize) and design principle 8 (nested governance) are difficult to fully incorporate into a federally run system. For large systems, it is unclear how the right to organize is different from participation in collective choice processes. Nested governance is challenging because, by definition, a federally run system concentrates decision making at the federal level, leaving less room for nested governance, although comanagement arrangements and other linkages are possible.

Challenges with some design principles at large scales also reflect the conclusions of Social-Ecological Systems Meta-Analysis Database (SESMAD) case studies (Epstein et al. 2014, Fleischman et al. 2014, Cox 2014, Evans et al. 2014). The SESMAD project seeks to determine if important variables, including the design principles, for small-scale systems can be effectively scaled up for large-scale governance systems (Cox et al. 2010). For example, an analysis of the Great Barrier Reef Marine Park similarly identified collective choice and rights to organize as problematic design principles for large-scale systems (Evans et al. 2014). The SESMAD case study of the International Convention for the Conservation of Atlantic Tuna also found that collective choice, rights to organize, and nested governance were either absent or unsuccessful on a large scale (Epstein et al. 2014). However, the authors posit that other mechanisms available at a federal scale, such as political dynamics and civil society interactions, may help to mitigate against governance failures (Epstein et al. 2014, Evans et al. 2014, Fleischman et al. 2014). Although some design principles were less applicable on a large scale, the majority of these attributes were equally applicable for small- and large-scale systems, indicating that they can be useful to assist in making management recommendations.

This analysis of Canadian RCAs contributes to a growing literature on scaling up small-scale governance variables for largescale systems. This information can help inform the creation of effective spatial management systems both in Canada and internationally. Our analysis offers important recommendations for projects that will also require high levels of social buy-in, ecological assessment, and monitoring. Internationally, information on scaling up successful common-pool resource management techniques could also offer guidance for existing RCA networks and spatial management systems.

Spatial management systems that address only one aspect of a conservation issue are consistently less effective than plans that consider a variety of social and ecological factors (Cox et al. 2010, Pollnac et al. 2010). Our analysis of BC's RCAs suggests that there is room for much social and ecological improvement of the management of RCAs. As a federally run system, these suggestions can be applied not only to RCAs but also existing spatial management systems. Furthermore, many countries are currently in the process of implementing federally run marine spatial management, and this analysis can serve as a guide for creating socially and ecologically effective marine conservation.

Responses to this article can be read online at: http://www.ecologyandsociety.org/issues/responses. $\mathrm{php} / 7815$

\section{Acknowledgments:}

This research was made possible with funding from SSHRC, a University of Victoria Graduate Fellowship from the School of Environmental Studies, and a Sara Spencer Foundation Research Award. Natalie C. Ban was supported by NSERC and SSHRC. We thank Frank Snelgrove and Neil Davis for sharing their insights on Canadian recreational and commercial fishing. Any errors or omissions are those of the authors.

\section{LITERATURE CITED}

Allison, G. W., J. Lubchenco, and M. H. Carr. 1998. Marine reserves are necessary but not sufficient for marine conservation. Ecological Applications 8(1):S79-S92. http://dx.doi.org/10.2307/2641365

Babcock, R. C., N. T. Shears, A. C. Alcala, N. S. Barrett, G. J. Edgar, K. D. Lafferty, T. R. McClanahan, and G. R. Russ. 2010. Decadal trends in marine reserves reveal differential rates of change in direct and indirect effects. Proceedings of the National Academy of Sciences of the United States of America 107 (43):18256-18261. http://dx.doi.org/10.1073/pnas.0908012107

Branch, T. A., R. Watson, E. A. Fulton, S. Jennings, C. R. McGilliard, G. T. Pablico, D. Ricard, and S. R. Tracey. 2010. The trophic fingerprint of marine fisheries. Nature 468(7322):431-435. http://dx.doi.org/10.1038/nature09528

Canadian Groundfish Research and Conservation Society (CGRCS). 2010. Sustainability. CGRCS, : Vancouver, British 
Columbia, Canada. [online] URL: http://www.cgrcs.com/ sustainability.html

Chalifour, L. 2012. GCA final report-freedom to swim: research component for rockfish recovery project. Report No. 11-8552. Galiano Conservancy Association, Galiano Island, British Columbia, Canada.

Claudet, J. and P. Guidetti. 2010. Improving assessments of marine protected areas. Aquatic Conservation 20(2):239-242. http://dx.doi.org/10.1002/aqc.1087

Claudet, J., C. W. Osenberg, L. Benedetti-Cecchi, P. Domenici, J.-A. García-Charton, A. Pérez-Ruzafa, F. Badalamenti, J. BayleSempere, A. Brito, F. Bulleri, J.-M. Culioli, M. Dimech, J. M. Falcón, I. Guala, M. Milazzo, J. Sánchez-Meca, P. J. Somerfield, B. Stobart, F. Vandeperre, C. Valle, and S. Planes. 2008. Marine reserves: size and age do matter. Ecology Letters 11(5):481-489. http://dx.doi.org/10.1111/j.1461-0248.2008.01166.x

Cloutier, R. N. 2010. Direct and indirect effects of marine protection: rockfish conservation areas as a case study. Thesis. Simon Fraser University, Burnaby, British Columbia, Canada.

Committee on the Status of Endangered Wildlife in Canada (COSEWIC). 2009a. COSEWIC assessment and status report on the Yelloweye rockfish, Sebastes ruberrimus: Pacific Ocean inside waters population, Pacific Ocean outside waters population in Canada. COSEWIC, Ottawa, Ontario, Canada.

Committee on the Status of Endangered Wildlife in Canada (COSEWIC). 2009b. COSEWIC assessment and status report on the Quillback Rockfish Sebastes maliger in Canada. COSEWIC, Ottawa, Ontario, Canada.

Cox, M. 2014. Understanding large social-ecological systems: introducing the SESMAD project. International Journal of the Commons 8(2):265-276.

Cox, M., G. Arnold, and S. Villamayor Tomás. 2010. A review of design principles for community-based natural resource management. Ecology and Society 15(4): 38. [online] URL: http:// www.ecologyandsociety.org/vol15/iss4/art38/

Davis, N. A. 2008. Evaluating collaborative fisheries management planning: a Canadian case study. Marine Policy 32(6):867-876. http://dx.doi.org/10.1016/j.marpol.2008.01.001

Dedual, M., O. Sague Pla, R. Arlinghaus, A. Clarke, K. Ferter, P. Geertz Hansen, D. Gerdeaux, F. Hames, S. J. Kennelly, A. R. Kleiven, A. Meraner, and B. Ueberschär. 2013. Communication between scientists, fishery managers and recreational fishers: lessons learned from a comparative analysis of international case studies. Fisheries Management and Ecology 20:234-246. http://dx. doi.org/10.1111/fme.12001

Epstein, G., M. Nenadovic, and A. Boustany. 2014. Into the deep blue sea: commons theory and international governance of Atlantic Bluefin Tuna. International Journal of the Commons 8 (2):277-303.

Essington, T. E., A. H. Beaudreau, and J. Wiedenmann. 2006. Fishing through marine food webs. Proceedings of the National Academy of Sciences of the United States of America 103 (9):3171-3175. http://dx.doi.org/10.1073/pnas.0510964103
Evans, L. S., N. C. Ban, M. Schoon, and M. Nenadovic. 2014. Keeping the 'Greatapo' in the Great Barrier Reef: large-scale governance of the Great Barrier Reef Marine Park. International Journal of the Commons 8(2):396-427.

Favaro, B., D. T. Rutherford, S. D. Duff, and I. M. Côté. 2010. Bycatch of rockfish and other species in British Columbia spot prawn traps: preliminary assessment using research traps. Fisheries Research 102(1):199-206. http://dx.doi.org/10.1016/j. fishres.2009.11.013

Fisheries and Oceans Canada (DFO). 2013. Pacific region. Integrated Fisheries Management Plan: groundfish. Fisheries and Oceans Canada, Vancouver, British Columbia, Canada. [online] URL: http://www.pac.dfo-mpo.gc.ca/fm-gp/mplans/2013/groundfond/ground-fond-2013-eng.pdf

Fisheries and Oceans Canada (DFO). 2014a. Rockfish Conservation Areas (RCAs)_Pacific region. Fisheries and Oceans Canada, Vancouver, British Columbia, Canada. [online] URL: http://www.pac.dfo-mpo.gc.ca/fm-gp/maps-cartes/rca-acs/ index-eng.html

Fisheries and Oceans Canada (DFO). 2014b. Sport Fish Advisory Board (SFAB). Fisheries and Oceans Canada, Vancouver, British Columbia, Canada. [online] URL: http://www.pac.dfo-mpo.gc. ca/consultation/smon/sfab-ccps/index-eng.html

Fisheries and Oceans Canada (DFO). 2015. Pacific region integrated fisheries management plans. Fisheries and Oceans Canada, Vancouver, British Columbia, Canada. [online] URL: http://www.pac.dfo-mpo.gc.ca/fm-gp/ifmp-eng.html

Fleischman, F. D., N. C. Ban, L. S. Evans, G. Epstein, G. GarciaLopez, and S. Villamayor-Tomás. 2014. Governing large-scale social-ecological systems: lessons from five cases. International Journal of the Commons 8:428-456.

Frid, A., B. Connors, A. B. Cooper, and J. Marliave. 2013. Sizestructured abundance relationships between upper- and midtrophic level predators on temperate rocky reefs. Ethology Ecology \& Evolution 25:253-268. http://dx.doi.org/10.1080/03949370.2013.798350

Gaines, S. D., S. E. Lester, K. Grorud-Colvert, C. Costello, and R. Pollnac. 2010a. Evolving science of marine reserves: new developments and emerging research frontiers. Proceedings of the National Academy of Sciences of the United States of America 107(43):18251-18255. http://dx.doi.org/10.1073/pnas.1002098107

Gaines, S. D., C. White, M. H. Carr, and S. R. Palumbi. $2010 b$. Designing marine reserve networks for both conservation and fisheries management. Proceedings of the National Academy of Sciences of the United States of America 107(43):18286-18293. http://dx.doi.org/10.1073/pnas.0906473107

Government of Canada. 2014a. Fisheries Act. Government of Canada, Ottawa, Ontario. Canada. [online] URL: http://lawslois.justice.gc.ca/eng/acts/f-14/

Government of Canada. 2014b. British Columbia Sport Fishing Regulations, 1996. Government of Canada, Ottawa, Ontario. Canada. [online] URL: http://laws-lois.justice.gc.ca/eng/regulations/ SOR-96-137I

Government of Canada. 2014c. Criminal Code. Government of Canada, Ottawa, Ontario. Canada. [online] URL: http://lawslois.justice.gc.ca/eng/acts/C-46/ 
Granek, E. F., E. M. P. Madin, M. A. Brown, W. Figueira, D. S. Cameron, Z. Hogan, G. Kristianson, P. de Villiers, J. E. Williams, J. Post, S. Zahn, and R. Arlinghaus. 2008. Engaging recreational fishers in management and conservation: global case studies. Conservation Biology 22(5):1125-1134. http://dx.doi.org/10.1111/ j.1523-1739.2008.00977.x

Haggarty, D. 2014. Rockfish conservation areas in BC: our current state of knowledge. David Suzuki Foundation, Vancouver, British Columbia, Canada. [online] URL: http://www.davidsuzuki.org/ publications/RockfishConservationAreas-OurCurrentStateofKnowledgeMar2014.pdf

Halpern, B. S. 2003. The impact of marine reserves: do reserves work and does reserve size matter? Ecological Applications 13 (1):117-137. http://dx.doi.org/10.1890/1051-0761(2003)013[0117: TIOMRD]2.0.CO;2

Hutchings, J. A. 2001. Conservation biology of marine fishes: perceptions and caveats regarding assignment of extinction risk. Canadian Journal of Fisheries and Aquatic Sciences 58(1):108-108. http://dx.doi.org/10.1139/f00-228

Hutchings, J. A., and J. D. Reynolds. 2004. Marine fish population collapses: consequences for recovery and extinction risk. BioScience 54(4):297-309. http://dx.doi.org/10.1641/0006-3568 (2004)054[0297:mfpccf]2.0.co;2

International Pacific Halibut Commission (IPHC). 2014. Advisory bodies. [online] URL: http://www.iphc.int/about-iphc. html\#advisors

Jackson, J. B. 2001. What was natural in the coastal oceans? Proceedings of the National Academy of Sciences of the United States of America 98(10):5411-5418. http://dx.doi.org/10.1073/ pnas.091092898

Keller, A. A., W. W. Wakefield, C. E. Whitmire, B. H. Horness, M. A. Bellman, and K. L. Bosley. 2014. Distribution of demersal fishes along the US west coast (Canada to Mexico) in relation to spatial fishing closures (2003-2011). Marine Ecology Progress Series 501:169-190. http://dx.doi.org/10.3354/meps10674

Kritzer, J. P. 2004. Effects of noncompliance on the success of alternative designs of marine protected-area networks for conservation and fisheries management. Conservation Biology 18 (4):1021-1031. http://dx.doi.org/10.1111/j.1523-1739.2004.00022. $\underline{x}$

Lacroix, K., and G. Richards. 2015. An alternative policy evaluation of the British Columbia carbon tax: broadening the applications of Elinor Ostrom's design principles for managing common-pool resources. Ecology and Society. 20(2): 38. http://dx. doi.org/10.5751/ES-07519-200238

Lotterhos, K. E., S. J. Dick, and D. R. Haggarty. 2014. Evaluation of rockfish conservation area networks in the United States and Canada relative to the dispersal distance for black rockfish (Sebastes melanops). Evolutionary Applications 7(2):238-259. http://dx.doi.org/10.1111/eva.12115

Lotze, H. K., H. S. Lenihan, B. J. Bourque, R. H. Bradbury, R. G. Cooke, M. C. Kay, S. M. Kidwell, M. X. Kirby, and C. H. Peterson. 2006. Depletion, degradation, and recovery potential of estuaries and coastal seas. Science 312(5781):1806-1809. http:// dx.doi.org/10.1126/science. 1128035

Love, M. S., M. H. Carr, and L. J. Haldorson. 1991. The ecology of substrate-associated juveniles of the genus Sebastes. Environmental Biology of Fishes 30:225-243. http://dx.doi. org/10.1007/BF02296891

Love, M. S., M. Yoklavich, and L. K. Thorsteinson. 2002. The rockfishes of the northeast Pacific. University of California Press, Oakland, California, USA.

Marliave, J., and W. Challenger. 2009. Monitoring and evaluating rockfish conservation areas in British Columbia. Canadian Journal of Fisheries and Aquatic Sciences 66(6):995-1006. http:// dx.doi.org/10.1139/F09-056

Mosquera, I., I. M. Côté, S. Jennings, and J. D. Reynolds. 2000. Conservation benefits of marine reserves for fish populations. Animal Conservation 3(4):321-332. http://dx.doi.org/10.1111/ j.1469-1795.2000.tb00117.x

Norse, E. A. 1993. Global marine biological diversity: a strategy for building conservation into decision making. Island Press, Washington, D.C., USA.

O'Connell, R. 2012. Reconciling participants' values in the Britsh Columbia Pacific halibut (Hippoglossus stenolepis) intersectoral allocation dispute. University of Akureyri, Akureyri, Iceland.

Ostrom, E. 1990. Governing the commons: the evolution of institutions for collective action. Cambridge University Press, Cambridge, UK.http://dx.doi.org/10.1017/cbo9780511807763 http:// dx.doi.org/10.1017/cbo9780511807763

Ostrom, E. 2009. A general framework for analyzing sustainability of social-ecological systems. Science 325 (5939):419-422. http://dx.doi.org/10.1126/science.1172133

Parker, S. J., S. A. Berkeley, J. T. Golden, D. R. Gunderson, J. Heifetz, M. A. Hixon, R. Larson, B. M. Leaman, M. S. Love, J. A. Musick, V. M. O'Connell, S. Ralston, H. J. Weeks, and M. M. Yoklavich. 2000. Management of Pacific rockfish. Fisheries 25 (3):22-30. http://dx.doi.org/10.1577\%2F1548-8446\%282000\%29025\% 3C0022\%3Amopr $\% 3 \mathrm{E} 2.0 . \mathrm{co} \% 3 \mathrm{~B} 2$

Parker, S. J., H. I. McElderry, P. S. Rankin, and R. W. Hannah. 2006. Buoyancy regulation and barotrauma in two species of nearshore rockfish. Transactions of the American Fisheries Society 135(5):1213-1223. http://dx.doi.org/10.1577/t06-014.1

Pauly, D., V. Christensen, J. Dalsgaard, R. Froese, and F. Torres, Jr. 1998. Fishing down marine food webs. Science 279 (5352):860-863. http://dx.doi.org/10.1126/science.279.5352.860

Pauly, D., V. Christensen, S. Guénette, T. J. Pitcher, U. R. Sumaila, C. J. Walters, R. Watson, and D. Zeller. 2002. Towards sustainability in world fisheries. Nature 418(6898):689-695. http:// dx.doi.org/10.1038/nature01017

Pollnac, R., P. Christie, J. E. Cinner, T. Dalton, T. M. Daw, G. E. Forrester, N. A. J. Graham, and T. R. McClanahan. 2010. Marine reserves as linked social-ecological systems. Proceedings of the National Academy of Sciences of the United States of America 107(43):18262-18265. http://dx.doi.org/10.1073/pnas.0908266107 
Robb, C. K., K. M. Bodtker, K. Wright, and J. Lash. 2011. Commercial fisheries closures in marine protected areas on Canada's Pacific coast: the exception, not the rule. Marine Policy 35(3):309-316. http://dx.doi.org/10.1016/j.marpol.2010.10.010

UK Government. 2014. Buy a fishing rod licence. Gov.uk, built by the Government Digital Service. [online] URL: https://www. gov.uk/fishing-licences/when-you-need-a-licence

Williams, G. D., P. S. Levin, and W. A. Palsson. 2010. Rockfish in Puget Sound: an ecological history of exploitation. Marine Policy 34(5):1010-1020. http://dx.doi.org/10.1016/j.marpol.2010.02.008

Worm, B., R. Hilborn, J. K. Baum, T. A. Branch, J. S. Collie, C. Costello, M. J. Fogarty, E. A. Fulton, J. A. Hutchings, S. Jennings, O. P. Jensen, H. K. Lotze, P. M. Mace, T. R. McClanahan, C. Minto, S. R. Palumbi, A. M. Parma, D. Ricard, A. A. Rosenberg, R. Watson, and D. Zeller. 2009. Rebuilding global fisheries. Science 325(5940):578-585. http://dx.doi.org/10.1126/science.1173146

Yamanaka, K. L., and G. Logan. 2010. Developing British Columbia's inshore rockfish conservation strategy. Marine and Coastal Fisheries 2(1):28-46. http://dx.doi.org/10.1577/c08-036.1 
Appendix 1. Ecological and social findings: extended summary from key RCA literature (see Table 5 for brief summary)

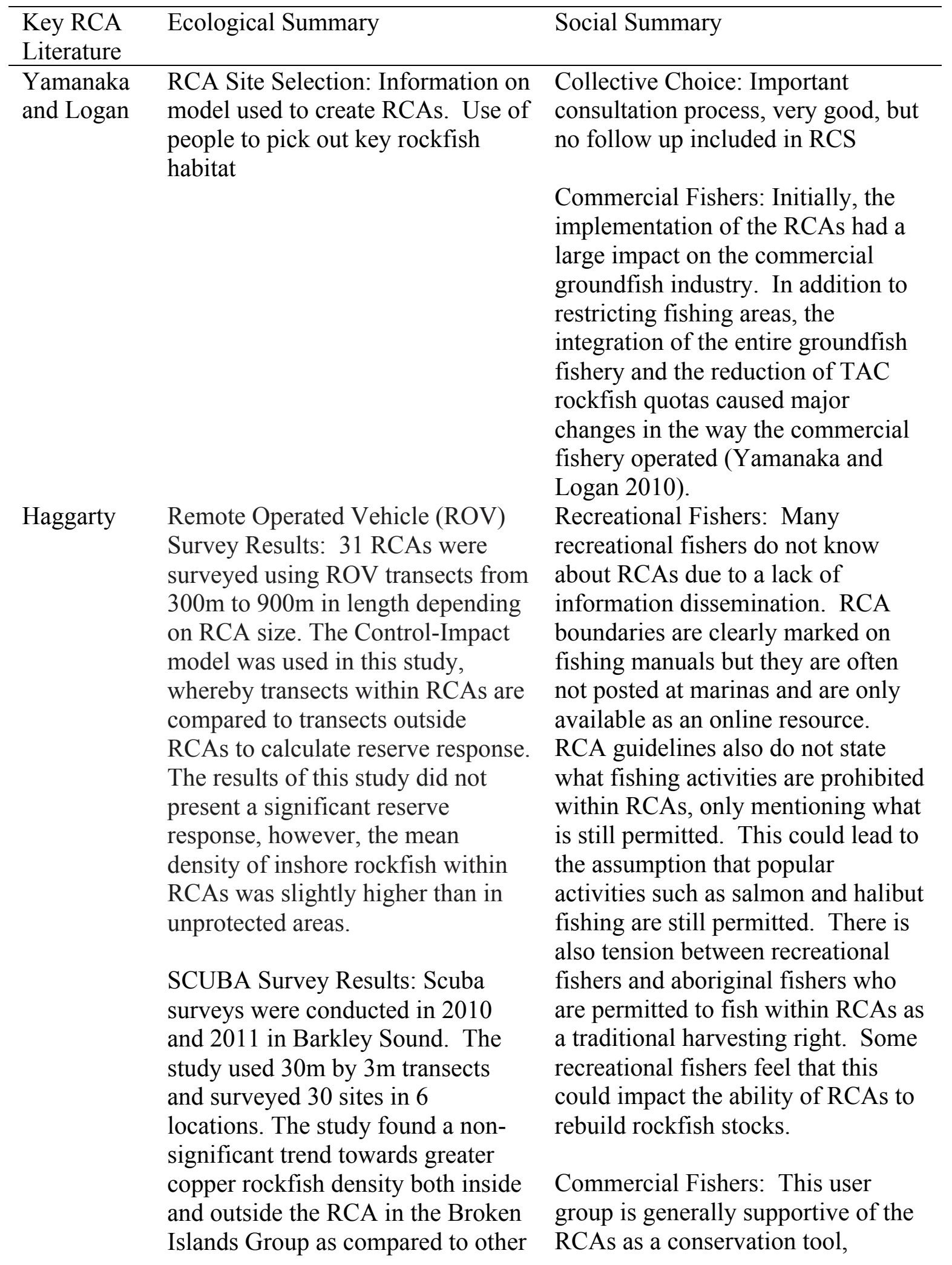




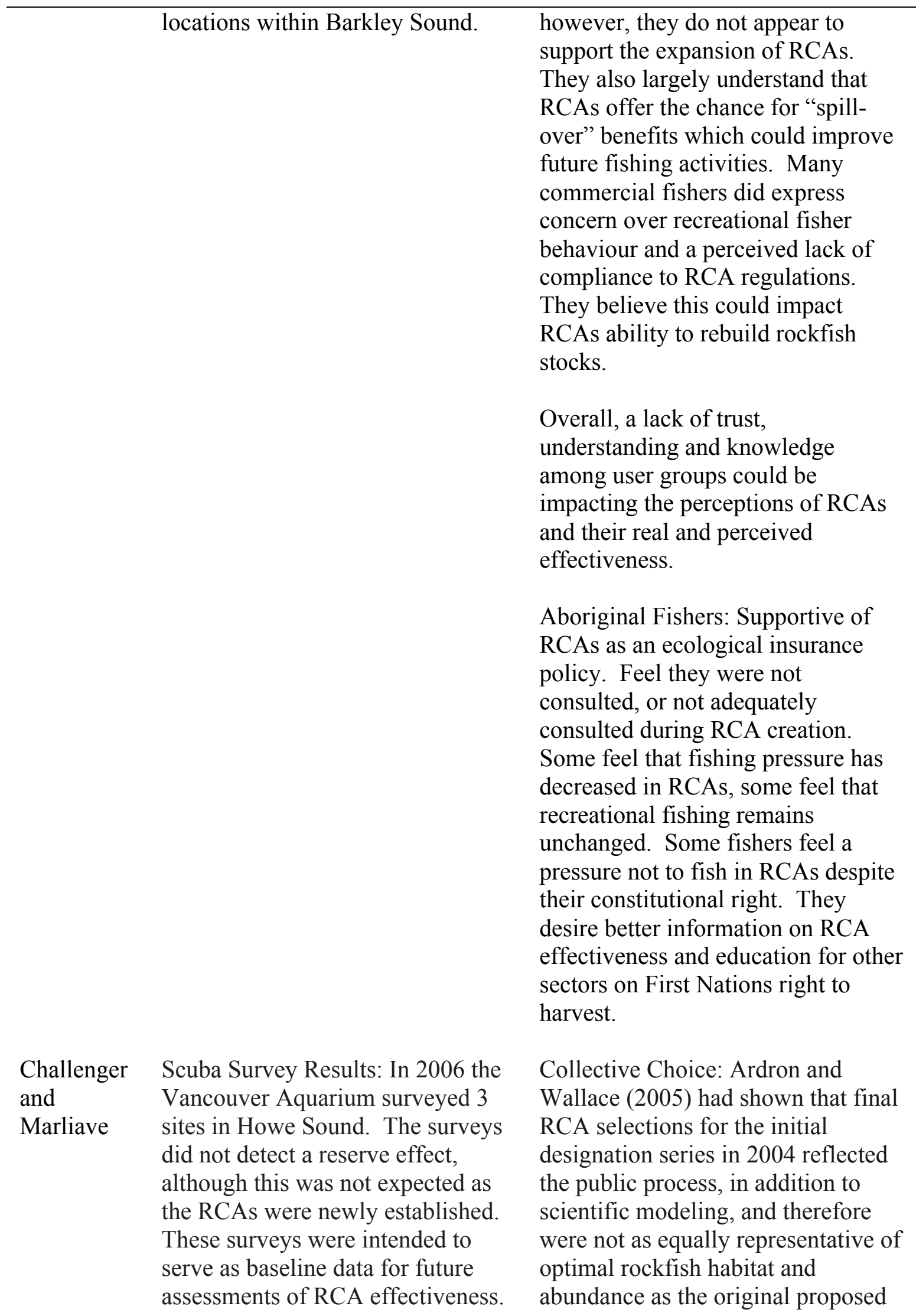


RCAs based on the model only.

Side-Scan Sonar Results: This study also determined that rockfish are strongly associated with piled boulder habitats that cannot easily be detected by the type of bathymetry data that was originally used to select RCA sites. This study concluded that these optimal rockfish sites can be detected using side-scan sonar.

Cloutier

Chalifour
Scuba Survey Results: This study was the first to research the effectiveness of RCAs in replenishing rockfish stocks. 15 sites were surveyed in Howe Sound, the Southern Gulf Islands, and the Central Strait of Georgia combined. The study found that RCAs had and average of 1.6 times more rockfish than unprotected sites. This study also accounted for differences in habitat. There was no correlation between rockfish density and age of RCAs. There was as significant difference between regional rockfish density, with Howe Sound showing the lowest levels of rockfish density.

Scuba Survey Results: Two RCAs around Galiano Island were surveyed using the Control-Impact method and $30 \mathrm{~m}$ by $1 \mathrm{~m}$ transects. The study found that rockfish density was much higher outside the RCAs, however, habitat variability was not considered in the research design which could impact results. The study also showed that some of the Galiano Island RCAs are located in unsuitable rockfish habitat, especially when compared to some unprotected survey sites with
Recreational Fishers: In addition to misunderstanding RCA regulations, recreational fishers are often unaware of where RCAs are located due to a lack of information dissemination This lack of knowledge and understanding has lead to confusion and at times illwill towards the RCAs as fishers are reprimanded by DFO officers or community members for fishing in areas they believe to be open access. 
optimal rockfish habitat. 
Appendix 2. Illustrative examples of Design Principle presence/absence rating for RCAs (Design principles $1 \mathrm{a}, 1 \mathrm{~b}$ and $2 \mathrm{a}$ ).

Table A2.1. Design Principles were ranked on a four point scale: Present - All aspects of the design principle's definition have been met; Moderately Present - The majority of the design principle's definition has been met - there is room for slight improvement; Lacking - The majority of the design principles's definition has not been met - small hints of the principle are reflected in the management system; Absent - No aspects of the design principle's definition have been met.

\begin{tabular}{|c|c|c|c|}
\hline $\begin{array}{l}\text { Design Principles } \\
\text { Definition }\end{array}$ & $\begin{array}{l}\text { Design Principle } \\
\text { Elements }\end{array}$ & $\begin{array}{l}\text { Recreational } \\
\text { Fishery: Elements } \\
\text { present and final } \\
\text { score }\end{array}$ & $\begin{array}{l}\text { Commercial } \\
\text { Fishery: Elements } \\
\text { present and final } \\
\text { score }\end{array}$ \\
\hline $\begin{array}{l}\text { 1a. Clear User } \\
\text { Boundaries: } \\
\text { Users must } \\
\text { clearly } \\
\text { understand who } \\
\text { may utilize the } \\
\text { resource and why } \\
\text { (i.e. Who can fish } \\
\text { within RCAs) }\end{array}$ & $\begin{array}{l}\text { 1. Regulations are } \\
\text { clearly defined. } \\
2 . \text { Users know } \\
\text { what the } \\
\text { regulations are. } \\
\text { 3. Users } \\
\text { understand why } \\
\text { regulations exist. }\end{array}$ & $\begin{array}{l}\text { Elements Present: } \\
\text { Only one element } \\
\text { of this design } \\
\text { principle is present } \\
\text { in the recreational } \\
\text { sector. }\end{array}$ & $\begin{array}{l}\text { Elements Present: } \\
\text { All elements of this } \\
\text { design principle } \\
\text { are present in the } \\
\text { commercial sector. } \\
\text { 1. Regulations are } \\
\text { clearly defined. } \\
\text { 2. Users know what } \\
\text { the regulations are. } \\
\text { 3. Users understand } \\
\text { why regulations } \\
\text { exist. } \\
\text { Score: Present }\end{array}$ \\
\hline $\begin{array}{l}\text { 1b. Clear } \\
\text { Resource } \\
\text { Boundaries: The } \\
\text { physical } \\
\text { boundaries } \\
\text { should be easily } \\
\text { visible (e.g. } \\
\text { marker buoys, } \\
\text { fences) or well } \\
\text { defined (e.g. clear } \\
\text { signs and maps in } \\
\text { prominent } \\
\text { locations). }\end{array}$ & $\begin{array}{l}\text { 1. Physical } \\
\text { boundaries are } \\
\text { clearly defined in } \\
\text { regulations. } \\
2 . \text { Physical } \\
\text { boundaries are } \\
\text { easily accessible } \\
\text { in regulations. } \\
\text { 3. Physical } \\
\text { boundaries are } \\
\text { clearly defined on } \\
\text { site (e.g. signs or } \\
\text { bouys) }\end{array}$ & $\begin{array}{l}\text { Elements Present: } \\
\text { Only one element } \\
\text { of this design } \\
\text { principle is present } \\
\text { in the recreational } \\
\text { sector. } \\
\text { 1. Physical } \\
\text { boundaries are } \\
\text { clearly defined in } \\
\text { regulations. } \\
\text { Score: Lacking }\end{array}$ & $\begin{array}{l}\text { 1. Physical } \\
\text { boundaries are } \\
\text { clearly defined in } \\
\text { regulations. } \\
\text { 2. Physical } \\
\text { boundaries are } \\
\text { easily accessible in } \\
\text { regulations. }\end{array}$ \\
\hline
\end{tabular}


Score: Moderately

Present

2a. Appropriate

Resource

Regulations:

Regulations must

match local

resource

conditions. The

rules regarding

when, how, and

where resources

can be used or

taken must be

based on the

limitations of the

resource itself.

(e.g. RCAs must

be designed to

effectively

protect rockfish

based on habitat

and biological

characteristics)
1. Fishing restrictions adequately protect the resource (rockfish).

2. RCA

boundaries protect high quality rockfish habitat.

3. RCAs are positioned to allow for maximum larval recruitment between areas.
Elements Present:

All three elements of this design principle were present for both the Recreational and Commercial sector. However, they all needed improvement on some level.

1. Fishing restrictions adequately protect the resource (rockfish). (Area for

improvement: Reconsider the use of prawn traps in RCAs)

2. RCA boundaries protect high quality rockfish habitat. (Area for improvement: Possible problems with the model used to predict rockfish habitat.)

3. RCAs are positioned to allow for maximum larval recruitment between areas. (Area for improvement: Further research is necessary to determine if these zones allow max. larval recruitment)

Score: Moderately Present 